\title{
Development and Validation of a Cooling Load Prediction Model
}

\author{
Abir Khabthani ${ }^{1}$, Leila Châabane ${ }^{2}$ \\ Université de Tunis El Manar \\ Ecole Nationale d'Ingénieurs de Tunis \\ Laboratoire Analyse, Conception \\ et Commande des Systèmes (LR11ES20) \\ 1002, Tunis, Tunisie
}

\begin{abstract}
In smart buildings, cooling load prediction is important and essential in the sense of energy efficiency especially in hot countries. Indeed, prediction is required in order to provide the occupant by his consumption and incite him to take right decisions that would potentially decrease his energy demand. In some existing models, prediction is based on a selected reference day. This selection depends on several conditions similarity. Such model needs deep analysis of big past data. Instead of a deep study to well select the reference day; this paper is focusing on a short sampling-rate for predicting the next state. So, this method requires less inputs and less stored data. Prediction results will be more close to the real state. In first phase, an hourly cooling load model is implemented. This model has as input current cooling load, current outside temperature and weather forecast to predict the next hour cooling consumption. To enhance model's performance and reliability, the sampling period is decreasing to 30 minutes with respect to system dynamic. Lastly, prediction's accuracy is improved by using previous errors between actual cooling load and prediction results. Simulations are realized in nodes located at a campus showing good adequacy with measurements.
\end{abstract}

Keywords-Smart building; energy efficiency; prediction; short sampling-rate; less stored data

\section{INTRODUCTION}

Research and innovation in the design of technologies to make buildings smart and intelligent have increased enormously during past decade [1]-[6]. Integration of information technologies and computation in Building Management System is an inevitable option. Such system makes easy and possible the on line environmental monitoring [7] and control of many activities and services associated to the building. The role of decision support systems is significant since it contributes to the continuous energy management of a typical building's daily operations, aiming to preserve occupants comfort conditions and minimize energy consumption and cost [8]. Indeed, energy and comfort trade-off in buildings is absorbing interest of many researches around the world. Various aspects of this research domain have been investigated so far [9]-[12]. Enormous attention should be paid to occupants' comfort which is a main concern for building's intelligence. Indeed, human beings spend most of their life in indoor areas (homes, schools, offices). Energy in building, in hot countries, is considered as among the main consumers. According to the Arab Union of Electricity, electricity consumption in residential sector represents $30 \%$ of total electricity consumption in Tunisia. The dominant energy consumption in hot countries is the cooling system especially during hot season. In this framework, the World Bank launched a study [13] in the context of a multi-donor trust fund for addressing climate change in the Middle East and the North Africa Region. According to this study, every year, about 2 million air conditioners are added in the Maghreb countries. In Tunisia, in residential sector, the installed capacity of cooling systems is equal to $2156 \mathrm{MW}$. It represents $69 \%$ of maximum power demand equal to $3144 \mathrm{MW}$. This significant increase of air conditioners causes the appearance of electric consumption peak and a structural change of the load curve during summer. The peak demand has increased by $5.1 \%$ annually. Therefore, any saving applied to such equipment has a great potential of energy reductions.

A large number of papers proposed various methods for cooling system's energy management [14]-[16]. The main approach highlighted in these papers is the cooling load prediction. Generally, these methods are physical model [17] [18], [19], black box model [20], [21] and grey box model [22], [23]. The physical model demonstrates good results but requires big data set, various types of weather data, a deep analysis of past data and extensive complex model. For instance, the model, developed in [24], needs several physical parameters and a considerable amount of details (type of internal mass according to its thermal mass and type of radiation it absorbs, detailed parameters of layers, etc.) and site data for identification of parameters. Sometimes, in such physical model, there are data which are difficult to obtain or even missing. Indeed, the authors in [25] proposed a cooling energy prediction model using an enthalpy-based cooling degree days method. Enthalpy calculation is a complex issue and needs some parameters hard to be available. In black box model, several methods achieved acceptable prediction results. However, its major problem is that prediction's reliability and accuracy depend on selected training data. Also, some black box models such as [26], [27] use sophisticated methods. The grey box model is known by its satisfactory reliability, low requirement of training data. However, this model should be improved in terms of computing power and error checking. Among these prediction models, cooling consumption is predicted by developing a method based on the selection of a reference day according to occupancy similarity principle. This prediction method depends also on a weather data which is the 
most correlated to current measurements. Then prediction results are calibrated by using the average error of past two hours. This model necessities a deep study to well select the reference day. Also, it requires as input a considerable amount of historical data. This paper therefore proposes a simplified cooling prediction model based on using current hour data as a reference for predicting the next hour consumption. So, the deep analysis of big past daily data and the issue of selecting a reference day are not required. Other enhancement is to decrease sampling period while respecting system response.

The content of this paper is organized as follows. Section 2 elaborates the computing of actual cooling load. Section 3 describes the analysis and modeling processes in this work. This section also discusses the simulations and the results. Section 4 presents the conclusion and the future work.

\section{COMPuting of Actual CoOling LoAD}

Nowadays, several strategies and technologies aim to respect the trade-off between energy and comfort and introduce this concept inside buildings. This approach brings intelligence to buildings. To ensure occupant's comfort, considered as a complicated problem, a new approach is highlighted in this paper. This approach is based on human decisions since a change in his behavior is a key in achieving sustained reductions in energy consumption. For these reasons, cooling consumption, considered as the dominant energy use especially in hot countries, must be predicted and provided to human with useful awareness tips. Indeed, if occupant will be aware of his predicted consumption, he will be able to take right decisions that respect energy management and his preference. Several papers developed various methods for cooling consumption prediction. Among these models, proposed in literature, we cite a load prediction method based on a selected reference day. Cooling consumption of this reference day is taken as the targeted day's initial load prediction result. With respect to smart buildings, this paper proposes a predicted cooling model based on a short-sampling rate during the same day. This prediction method gives occupant fast analyses and drives his behavior in favor of his comfort and his consumption.

The building, proposed as a case of study, is composed of identical rooms. These nodes are illustrated by Fig. 1. $\mathrm{T}_{1}$ and $\mathrm{T}_{2}$ are adjacent rooms' temperatures. $\mathrm{T}_{0}$ is the concerned node's temperature. They are given in degrees Celsius.

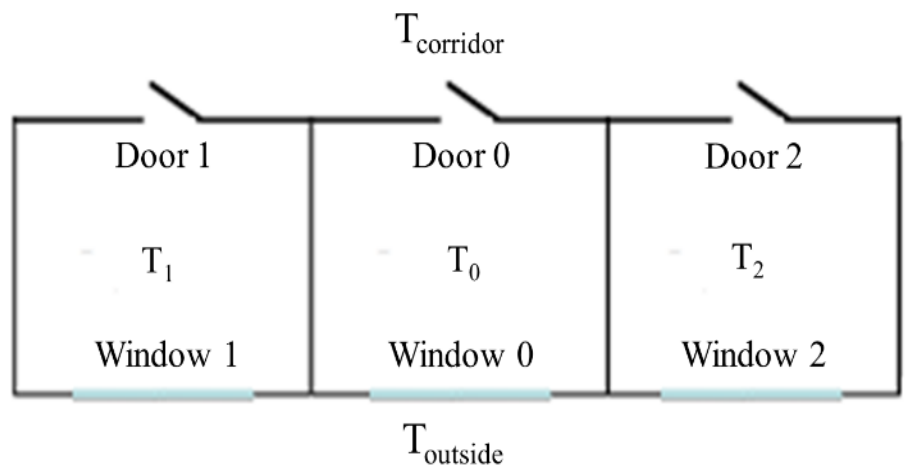

Fig. 1. Node's top view.
Model's simulations have been tested in one node located between two other similar rooms, exposed to solar radiation through windows' glasses and equipped with an air conditioner and temperature sensors. Measurements are done during a significant day in hot season.

A data acquisition system (DAQ) has been realized to measure temperature exchanges: inside temperature, outside temperature, corridor's temperature and adjacent rooms' temperature. This DAQ is composed of:

- microcontroller board based on the ATmega328P,

- memory card reader, and

- temperature sensor DS1821.

The choice of this sensor is justified by its accuracy and its measurement range which is between $-55^{\circ} \mathrm{C}$ and $+125^{\circ} \mathrm{C}$. Five DAQs are positioned in different measurement points (concerned node, adjacent rooms, corridor and outside) to measure temperatures in a short sampling period. Indeed, a data logging solution is implemented in the microcontroller ATmega328P. This application serves to measure temperatures by sensors DS1821 and store these data in memory card reader.

The air conditioner worked with a set temperature equal to $21^{\circ} \mathrm{C}$ according to the standard ISO 7730 (Ergonomics of the thermal environment-Analytical determination and interpretation of thermal comfort using calculation of the Predicted Mean Vote (PMV) and the Predicted Percentage Dissatisfied (PPD) indices and local thermal comfort effects). Indoor temperature's sensor was added to calibrate the model. Indeed, to validate predicted cooling consumption, the first step was to determine actual consumption during a day.

To do so, a thermal model is proposed and detailed in the following. This model consists of resistors, capacitors, current source and voltage sources. Its input are data provided from temperature sensors. Its output is the computing of actual cooling consumption. Temperature is modelled by a voltage source, conduction and convection through walls, door and windows are modelled by resistors and capacitors.

Solar radiation is modelled by a current source. Its model is based on the difference between maximum and minimum outside temperature during a small sampling period in order that the model will be closed to the real state. Instead of computing a daily estimation of solar radiation (HS model) [28], [29] that may yield inaccurate results, this paper is focusing on a short-sampling rate. Indeed, in hot seasons, temperature gap is important during a short period. Solar radiation's model depends in turn on temperature variation.

This model is given by (1). Since windows are uncoated single glazing, the solar heat gain coefficient $S H G C$ is equal to 0.7. Also, the building, proposed as a case of study, is located in coastal region. Hence, the coefficient $K$ is equal to 0.19 .

$$
Q_{\text {rad }}=S H G C \times S_{f} \times K \times G_{0} \times\left(T_{\max }-T_{\min }\right)^{0.5}
$$

Where $S H G C$ is the Solar Heat Gain Coefficient equal to 0.7 [30], $S_{f}$ is the window area equal to $7.4 \mathrm{~m}^{2}, K$ is an 
empirical coefficient ( 0.16 for interior regions and 0.19 for coastal ones), $G_{0}$ is the hourly extra-terrestrial radiation $\left(\mathrm{W} / \mathrm{m}^{2}\right), T_{\max }$ is the maximum temperature and $T_{\min }$ is the minimum temperature.

The hourly extra-terrestrial radiation $G_{0}$ is computed by (2) [28]:

$$
\begin{aligned}
& G_{0}=\frac{12}{\pi} \times S C \times f \times\left(\cos \varphi \times \cos \delta \times\left(\sin \omega_{2}-\sin \omega_{1}\right)\right. \\
& \left.+\frac{\pi}{180} \times\left(\omega_{2}-\omega_{1}\right) \times \sin \varphi \times \sin \delta\right)
\end{aligned}
$$

Where $S C$ is the solar constant equal to $1367, f$ is the eccentricity correction factor, $\varphi$ is the latitude equal to $36.82^{\circ}$, $\omega_{1}$ is the solar hour angle for the beginning time, $\omega_{2}$ is the solar hour angle for the ending time and $\delta$ is the solar declination. Angles are given in degrees.

Eccentricity correction factor is described as follows:

$$
f=1+0.033 \times \cos \frac{360 \times n}{365}
$$

Where $n$ is day of the year (for example $1^{\text {st }}$ January corresponds to 1).

Solar declination is calculated by (4):

$$
\delta=23.45 \times \sin \left(360 \times \frac{284+n}{365}\right)
$$

Solar hour angle is the sun's angular deviation from south. It is expressed as follows:

$$
\omega=15^{\circ} \times(\text { Solar_Time }-12)
$$

$-180^{\circ} \leq \omega \leq 180^{\circ}$, negative before Solar Noon.

Since measurements are done between 6:00 and 14:00, solar hour angles $\omega$ are given by Table I.

\section{TABLE I. SOLAR HOUR ANGLES}

\begin{tabular}{|l|l|l|l|l|l|l|l|l|}
\hline $6 \mathrm{~h}$ & $7 \mathrm{~h}$ & $8 \mathrm{~h}$ & $9 \mathrm{~h}$ & $10 \mathrm{~h}$ & $11 \mathrm{~h}$ & $12 \mathrm{~h}$ & $13 \mathrm{~h}$ & $14 \mathrm{~h}$ \\
\hline-90 & -75 & -60 & -45 & -30 & -15 & 0 & 15 & 30 \\
\hline
\end{tabular}

After defining analysis data (building parameters and data provided by temperature sensors) and modelling solar radiation during a short sampling rate, a thermal model is proposed in Fig. 2. Where Rwij, Cwi, Rhij and Ti are the parameters of adjacent rooms having same conditions (wall resistor, wall capacitor, convection resistor and node's temperature), Rhci, Rwci and Cwc are the corridor wall's parameters, Rhoi, Rwoi, Cwo are the outside wall's parameters, Rwin is the window's resistor, Qrad is the solar radiation's source and $T_{0}$ is the indoor temperature.

Thermal model's parameters are given by Table II.
TABLE II. THERMAL MODEL'S PARAMETERS

\begin{tabular}{|c|c|}
\hline Parameters & Values \\
\hline \multicolumn{2}{|c|}{ Resistances (K/W) } \\
\hline Rwin & 0.310 \\
\hline Rwij & 0.07 \\
\hline Rhij & 0.113 \\
\hline Rhci & 0.0106 \\
\hline Rwoi & 0.0155 \\
\hline Rho2 & 0.520 \\
\hline Rho1 & 0.0518 \\
\hline \multicolumn{2}{|c|}{ Capacitance (J/K) } \\
\hline Cwi & 0.029 \\
\hline Cwc & 266463.28 \\
\hline Cwo & 182746.1 \\
\hline \multicolumn{2}{|c|}{} \\
\hline
\end{tabular}

Variation of indoor temperature depends on outside temperature, corridor temperature and adjacent nodes temperature. Since thermal model's output is the computing of actual cooling consumption, this last depends in turn on indoor temperature variation.

Actual cooling load is given by Fig. 3. Where, 0s is the beginning time corresponding to 6:00. The ending time is 28800 s which corresponds to $14: 00$. This period corresponds to the work hours (7:00 to 14:00). The air conditioner starts running one hour before.

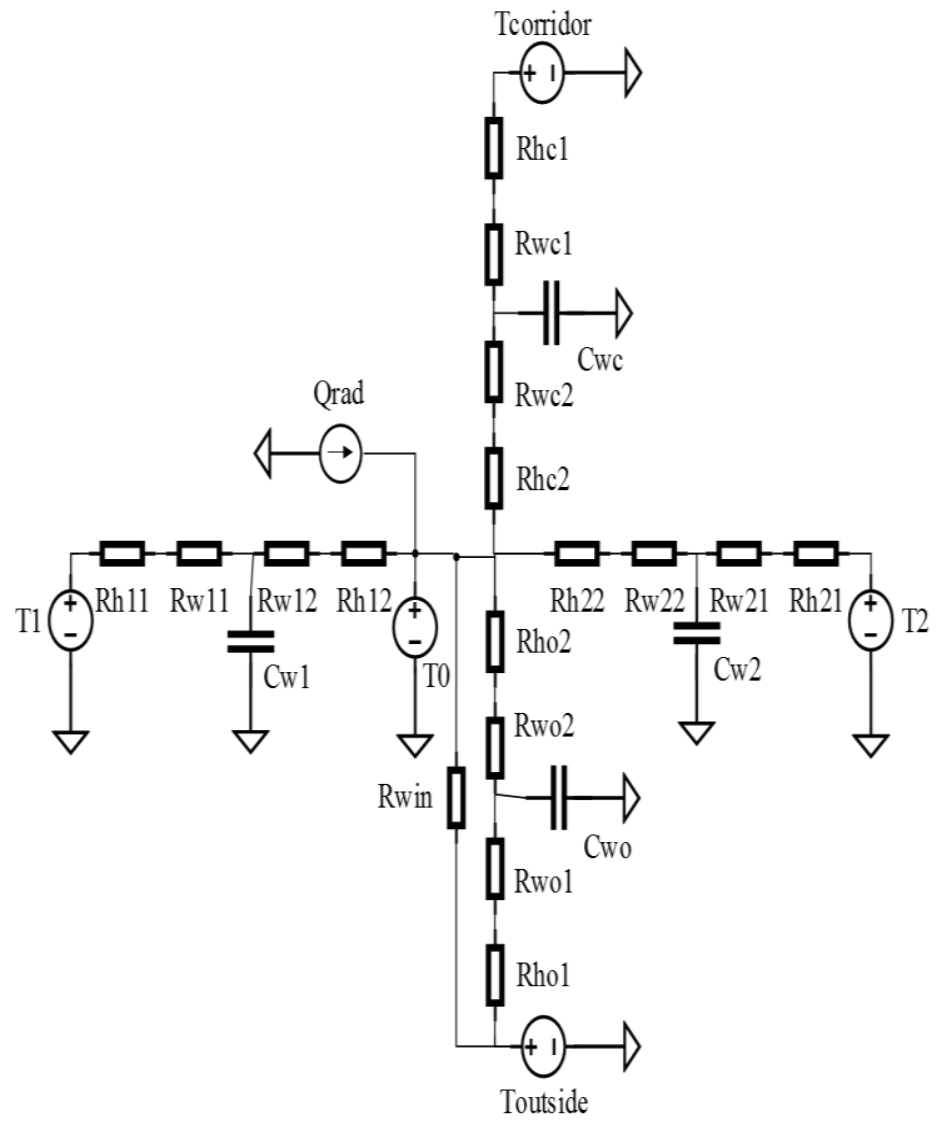

Fig. 2. Thermal model. 


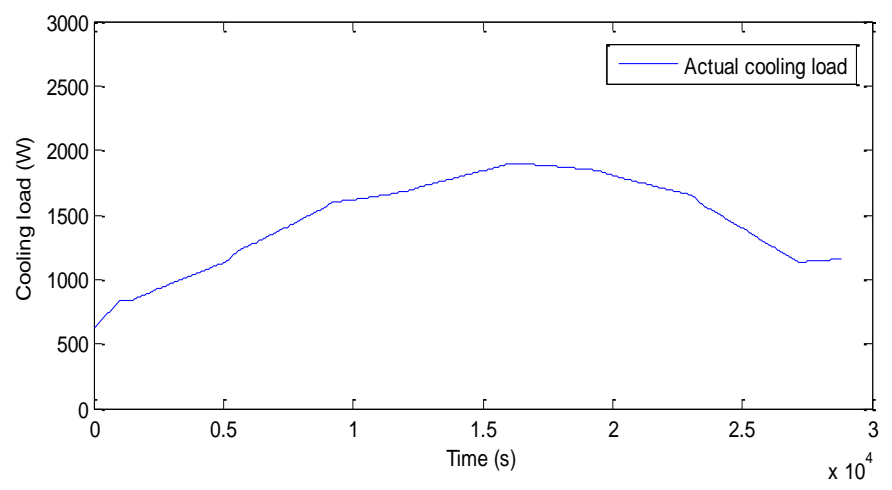

Fig. 3. Actual cooling load between 6:00 and 14:00.

\section{COOLING LOAD PREDICTON MOdEL}

Load prediction method, based on the selection of a reference day according to similarities in occupancy schedule, used an enormous amount of historical data (cooling load and weather data). Then, the model is calibrated by using errors of previous two hours between the predicted cooling load and the actual one.

Modifications were attributed to this model. Certainly, current model requires a deep analysis of great past data. Hence, the model isn't close to reality due to big historical data. Another model's difficulty is how to select the reference day. Indeed, this selection is a complicated issue for some residential buildings because it depends on several parameters essentially environmental conditions. However, in the proposed model, it's enough to deal with current hourly data to predict the next hour cooling load. So, paper's value-added is reducing the amount of data, which presents model's inputs, and discarding the issue of reference day. To enhance model's performance, previous errors are used for calibration. Details will be explained in the following:

In order to predict hourly cooling load during a day, the model requires following inputs:

- $Q_{\text {cooling/act }}^{t}$

: reference actual cooling load at time $\mathrm{t}$

- $T_{a c t}^{t}$

: reference actual outside temperature at

- $T_{\text {pre }}^{t+1 h}$ time $\mathrm{t}$

- cte : coefficient

Predicted cooling load for the next hour $Q_{\text {cooling/pre }}^{t+1 h}$ is given by (6). Predicted outside temperature $T_{p r e}^{t+1 h}$ are deduced from weather forecast. The coefficient cte is determined by the least square regression algorithm and equal to 0.81 . Since measurements are done between 6:00 and 14:00, actual cooling load consumption during the first hour $(6: 00-7: 00)$ is used as prediction's initial vector.

$$
Q_{\text {cooling/pre }}^{t+1 h}=Q_{\text {cooling/act }}^{t} \times\left(1+\text { cte } \times \frac{T_{\text {pre }}^{t+1 h}-T_{\text {act }}^{t}}{T_{\text {act }}^{t}}\right)
$$

The errors of previous two hours between prediction results and actual cooling load are used to enhance model's accuracy. To do so, the average error of past two hours $\Delta Q_{\text {cooling/t }}$ is added to the predicted cooling load at time $\mathrm{t}$ plus one hour $Q_{\text {cooling/pre }}^{t+1 h}$. This calibration method is given as follows:

$$
\begin{gathered}
Q_{\text {cooling/final }}^{t+1 h}=Q_{\text {cooling/pre }}^{t+1 h}+\Delta Q_{\text {cooling/t }} \\
\Delta Q_{\text {cooling/t }}=\frac{1}{2} \times(\text { error }(t)+\text { error }(t-1 h)) \\
\Delta Q_{\text {cooling/t }}=\frac{1}{2} \times\left(\left(Q_{\text {cooling/act }}^{t}-Q_{\text {cooling/pre }}^{t}\right)\right. \\
\left.+\left(Q_{\text {cooling/act }}^{t-1 h}-Q_{\text {cooling/pre }}^{t-1 h}\right)\right)
\end{gathered}
$$

For the second predicted hour, only the one hour previous error is used. To resume the proposed prediction model, current hourly consumption is sufficient for predicting the next hour cooling load. The second step is to enhance prediction by using average errors of past two hours between actual cooling load and prediction results. That's why, historical data of the previous hour ( $\mathrm{t}$ minus one hour) and current cooling consumption at time $\mathrm{t}$ must be available. Load prediction model's data are illustrated in Fig. 4. Where, $t$ is a reference time for predicting the next hour cooling load at time t plus one hour. So, this prediction is not an average hourly prediction but each instant $t$ is used for computing the next hour consumption (t plus one hour).

Model's simulations are illustrated by Fig. 5. The first hour is used as prediction's initial vector. This justifies that the starting point of predicted cooling load is 7:00. There is a gap between the actual cooling load and the predicted one. To evaluate model's accuracy, the mean relative error $M R E$ between predicted hourly cooling load and actual one is computed.

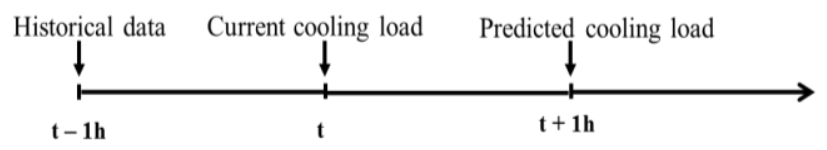

Fig. 4. Load prediction model's data.

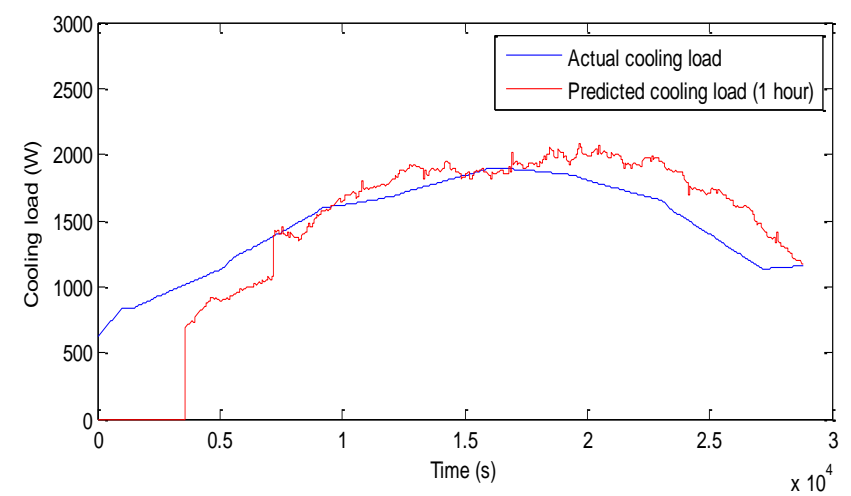

Fig. 5. Cooling load prediction based on a short sampling period equal to one hour. 
This $M R E$ is expressed by (10):

$$
\begin{gathered}
M R E=\frac{\sum_{k=1}^{N}\left|Q_{\text {cooling/act }}^{k}-Q_{\text {cooling/pre }}^{k}\right|}{\sum_{k=1}^{N}\left|Q_{\text {cooling/act }}^{k}\right|} \\
M R E_{1 H}=11.11 \%
\end{gathered}
$$

Where, $N$ is the number of data points.

According to $M R E$, there is a remaining gap essentially during consumption peak. In fact, the node, proposed as a case of study, is located in the east. So, in the morning, the node is too sunny especially during the period (11:00 - 12:00) consequently cooling load consumption is significant. This justifies the presence of consumption peak. Due to the peak's important derivative, the sampling period should be decreased to minimize the gap between predicted results and actual cooling load.

Hence, the model has undergone some refinements that will be detailed in the following. In order to minimize this error, modifications were attributed to the hourly model. Instead of using hourly data, the sampling period was decreased to thirty minutes while respecting system response.

Indeed, this study deals with smart buildings targeted applications and shows consideration for real time constraints so that this paper is focusing on a short-sampling rate to be close to the real state. This justifies the sampling period's choice. Cooling load prediction model becomes:

$$
Q_{\text {cooling/pre }}^{t+30 \min }=Q_{\text {cooling/act }}^{t} \times\left(1+\text { cte } \times \frac{T_{\text {pre }}^{t+30 \mathrm{~min}}-T_{a c t}^{t}}{T_{\text {act }}^{t}}\right)
$$

Where $Q_{\text {cooling/pre }}^{t+30 \min }$ is the predicted cooling load for the next thirty minutes, and $T_{p r e}^{t+30 \mathrm{~min}}$ is the predicted outside temperature for the next thirty minutes.

This proposed method is about to deal with current data to predict next cooling consumption after thirty minutes. Model's accuracy was enhanced by adding the average error of two previous 30 minutes.

Equations (8) and (9) are rewritten as follows:

$$
\begin{gathered}
\Delta Q_{\text {cooling/t }}=\frac{1}{2} \times(\text { error }(t)+\operatorname{error}(t-30 \mathrm{~min})) \\
\Delta Q_{\text {cooling/t }}=\frac{1}{2} \times\left(\left(Q_{\text {cooling/act }}^{t}-Q_{\text {cooling/pre }}^{t}\right)\right. \\
\left.+\left(Q_{\text {cooling/act }}^{t-30 \mathrm{~min}}-Q_{\text {cooling/pre }}^{t-30 \mathrm{~min}}\right)\right)
\end{gathered}
$$

Through simulations given by Fig. 6, the 30 minutes model has largely improved cooling load prediction showing good adequacy between actual consumption and prediction results. This enhancement is substantiated by computing $M R E$.

$$
\begin{gathered}
M R E_{30 \min }=4.52 \% \\
\frac{M R E_{1 H}}{M R E_{30 \min }}=2.46
\end{gathered}
$$

This criterion highlights that prediction based on a short sampling period, fixed according to system response, has calibrated the model and enhanced its performance. In order to evaluate the proposed model's performance, it's compared with cooling load prediction model developed in [24]. This existing model's $M R E$ is equal to $9.50 \%$. Whereas, through (15), MRE is equal to $4.52 \%$. Hence, the prediction model based on a short sampling period equal to thirty minutes is more accurate than the existing model. The proposed prediction model's methodology is also compared to other cooling load prediction based on physical model [19]. This latter approach may be sophisticated since it requires several thermal parameters, a deep physical representation of the building and extensive complex model. The development and validation of such approach are difficult due to several details involved and to a considerable amount of data hard to be measured or obtained. However, the prediction model, developed in this paper, is simplified and only depends on current data which are easily available.

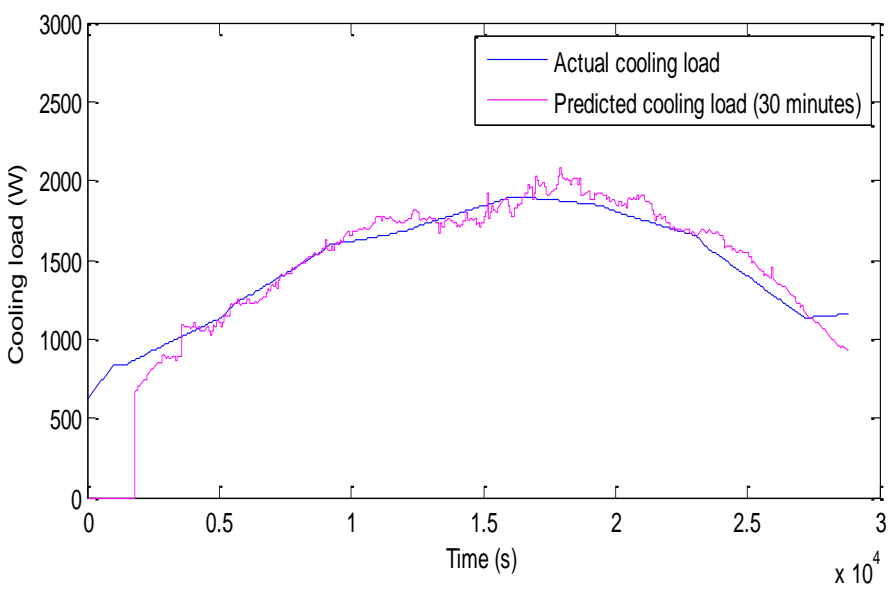

Fig. 6. Cooling load prediction model based on a short sampling period equal to 30 minutes (first significant day).

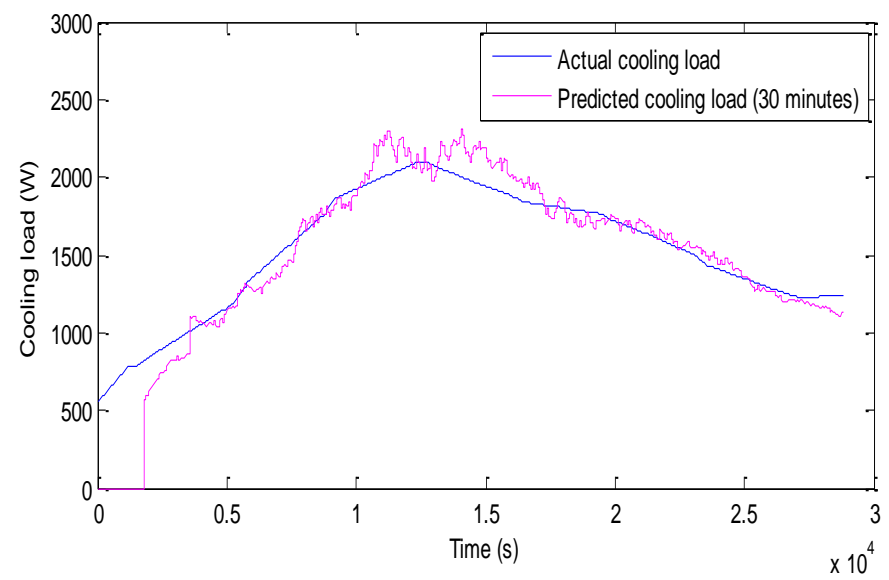

Fig. 7. Cooling load prediction model based on a short sampling period equal to 30 minutes (second significant day). 


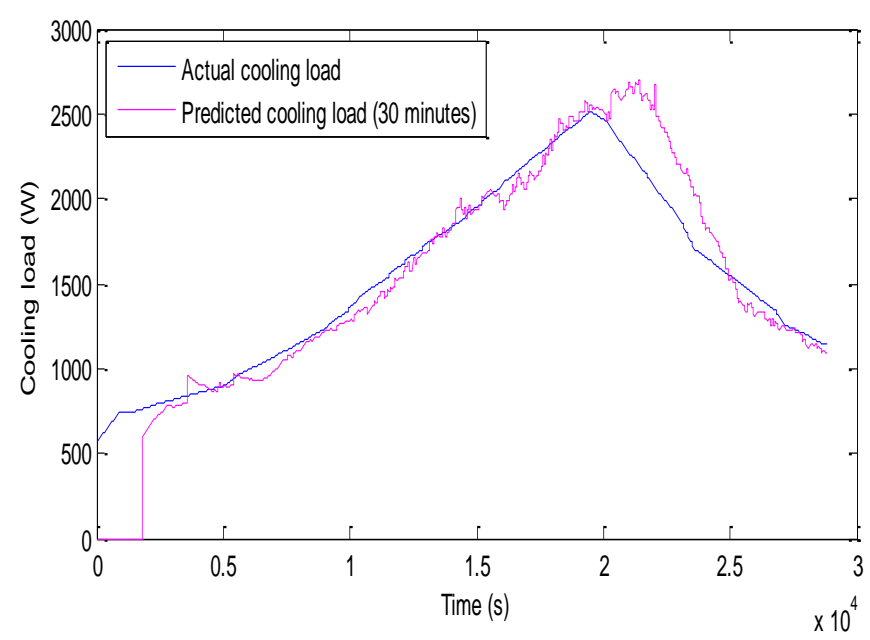

Fig. 8. Cooling load prediction model based on a short sampling period equal to 30 minutes (third significant day)

To generalize this proposed prediction, simulations, illustrated by Fig. 7 and 8, are applied to other significant days. These figures underscore that this prediction cooling model is valid even in other circumstances since meteorological parameters may vary enormously from a day to another due to their random fluctuation.

\section{CONCLUSION}

A cooling load prediction model, based on a short sampling rate, is developed in this paper. In first phase, it's about an hourly prediction. So, the model depends on current hourly data used as a reference to predict the next hour consumption. To calibrate this model, previous errors between prediction results and actual cooling load are helpful to enhance prediction's accuracy. Other enhancement is to decrease the sampling period to 30 minutes with respect to system response. Prediction has largely enhanced with $M R E$ equal to $4.52 \%$.

To validate the proposed method, actual cooling consumption is computed. Since this consumption mainly depends on solar radiation, this last is estimated during a small sampling period with respect to smart buildings. Solar radiation model is based on the difference between maximum and minimum outside temperature during a short-sampling rate.

Simulations have been done in rooms located at National Engineering School of Tunis in real conditions and have shown good adequacy with measurements.

In perspective, this model can be generalized in the whole building while taking account several details such as building structure, orientation according the sun, windows' sizes and number and wall material of each local... . This prediction model can be also enhanced by involving other parameters such as natural ventilation and blinds' position.

As far as further work on the prediction issue, heating systems, considered as the dominant energy use in cold countries, deserves attention to be studied and analyzed in the sense of energy reductions. So, the proposed prediction model will be expanded and applied to the sector of heating load.

\section{REFERENCES}

[1] Quoc-Dung, N., Yanis, H. S., Stéphane, P., Ujjwal, M., Md., "Automation generation of model for building energy management", International Journal of Advanced Computer Science and Applications (IJACSA), Vol. 7, No. 9, 2016.

[2] Yasser, M. A., Muhammad, N. K., "Simulation of building evacuation: performance analysis and simpliied model", International Journal of Advanced Computer Science and Applications (IJACSA), Vol. 7, No. 8, 2016.

[3] Eunji, L. and Hyokyung, B., "Electricity usage scheduling in smart building environments using smart devices", The Scientific World Journal, Vol. 2013.

[4] Fazli, W. and Do, H. K., "An efficient approach for energy consumption optimization and management in residential building using artificial bee colony and fuzzy logic", Mathematical Problems in Engineering, 2016.

[5] Thomas, M. L., Richard, T. W., Marie-Claude, B. and Javad, M., "Data flow requirements for integrating smart buildings and a smart grid through model predictive control", Procedia Engineering, Vol. 180, pp. 1402-1412, 2017.

[6] Rigo-Mariani, R., Roccuzzo, V., Sareni, B., Repetto, M. and Robaum, $\mathrm{X}$., "Power flow optimization in a microgrid with two kinds of energy storage", COMPEL: The International Journal for Computation and Mathematics in Electrical and Electronic Engineering, Vol. 35, pp. 860870, 2016.

[7] Jonathan, R. T., Nicholas J. K., Travis, M. A. and Tat, S. F., "Wireless sensor system for detection of occupants to increase building energy efficiency", Smart Cities Conference (ISC2), 2016 IEEE International, Italy, 2016.

[8] Bin, Z., Wentao, L., Ka, W. C., Yijia, C., Yonghong, K., Xi, L. and Xiong W., "Smart home energy management systems: concept, configurations, and scheduling strategies", Renewable and Sustainable Energy Reviews, Vol. 61, pp. 30-40, 2016.

[9] Althaher, S., Mancarella, P. and Mutale, J., "Automated Demand Response From Home Energy Management System Under Dynamic Pricing and Power and Comfort Constraints", IEEE Transactions on Smart Grid, Vol. 6, pp. 1874-1883, 2015.

[10] Yaser, I. A., Maria, d. M. C., José, D. A. and Antonio, R., "An economic model-based predictive control to manage the users' thermal comfort in a building", Energies, 10(3), 321, 2017.

[11] Fakeha, S., Manisa, P. and Saifur, R., "Integrated automation for optimal demand management in commercial buildings considering occupant comfort", Sustainable Cities and Society, Vol. 28, pp. 16-29, 2017.

[12] Kan, E. M., Kan, S. L., Ling, N. H., Soh, Y., Lai, M., "Multi-zone building control system for energy and comfort management", Hybrid Intelligent Systems, Advances in Intelligent Systems and Computing, Vol. 420. pp. 41-51, 2015.

[13] Khalfallah, E., Missaoui, R. El Khamlichi, S. and Ben Hassine, H., "Energy-efficient air conditioning: a case study of the Maghreb", the European Union, ESMAP and the World Bank, Washington, 2016.

[14] Sun, Y., Wang, S. and Xiao, F., "Development and validation of a simplified online cooling load prediction strategy for a super high-rise building in Hong Kong", Energy Conversion and Management, Vol. 68, pp. 20-27, 2013.

[15] Amjad, A. M., Hassan, M. and Ashkan, R. K., "Optimal smart home energy management considering energy saving and a comfortable lifestyle", IEEE Transactions on Smart Grid, Vol. 6, pp. 324-332, 2014.

[16] Riccardo, M. V., Francesco, B., Luigi, P., Martin, S. and Maria, P., "Energy management of a building cooling system with thermal storage: an approximate dynamic programming solution", IEEE Robotics and Automation Society, Vol. 14, pp. 619-633, 2017.

[17] Nada, S. A., Elfeky, K. E. and Attia, A. M. A., "Experimental investigatioons of air conditioning solutions in high power density data centers using a scaled physical model", International Journal of Refrigeration, Vol. 63, pp. 87-99, 2016.

[18] Ma, Y., Matusko, J. and Borrelli, F., "Stochastic model predictive control for building HVAC systems: complexity and conservation", IEEE Transactions on Control Systems Society, Vol. 23, pp. 101-116, 2015. 
[19] Sandels, C., Brodén, D., Widén, J., Nordstrom, L. and Andersson, E., "Modeling office building consumer load with a combined physical and behavioral approach: Simulation and validation", Applied Energy, Vol. 162, pp. 472-485, 2016.

[20] Afram, A. and Janabi-Sharifi, F., "Theory and applications of HVAC control systems - A review of model predictive control (MPC)", Building and Environment, Vol. 72, pp. 343-355, 2014.

[21] Coakley, D., Raftery, P. and Keane, M., "A review of methods to match building energy simulation models to measured data", Renewable and Sustainable Energy Reviews, Vol. 37, pp. 123-141, 2014.

[22] Coninck, R. D., Magnusson, F., Akesson, J. and Helsen, L., "Toolbox for development and validation of grey-box building models for forecasting and control", Journal of Building Performance Simulation, Vol. 9, pp. 288-303, 2015.

[23] Maomao, H. and Fu, X., "Investigation of the demand response potentials of residential air conditioners using grey-box room thermal model", Energy Procedia, Vol. 105, pp. 2759-2765, 2017.

[24] Ying, J., Peng, X., Pengfei, D. and Xing, L., "Estimating hourly cooling load in commercial buildings using a thermal network model and electricity submetering data", Applied Energy, Vol. 169, pp. 309-323, 2016.
[25] Minjae, S., and Sung, L. D., "Prediction of cooling energy use in buildings using an enthalpy-based cooling degree days method in a hot and humid climate", Energy and Buildings, Vol. 110, pp. 57-70, 2016.

[26] Chirag, D., Lee, S. E., Junjing, Y. and Mattheos, S., "Forecasting Energy consumptivn of institutional buildings in Singapore", Procedia Engineering, Vol. 121, pp. 1734-1740, 2015.

[27] Radu, P., Vahid, R. D. and Jacques, M., "Hourly prediction of a building's electricity consumption using case-based reasoning, artificial neural networks and principal component analysis", Energy and Buildings, Vol. 92, pp. 10-18, 2015.

[28] Yacef, R., Mellit, A., Belaid, S., and Sen, Z., "New combined models for estimating daily global solar radiation from measured air temperature in semi-arid climates: Application in Ghardaia, Algeria", Energy Conversion and Management, Vol. 79, pp. 606-615, 2014.

[29] Daut, I., Irwanto, M., Irwan, Y. M., Gomesh, N. and Ahmad, N. S., "Combination of Hargreaves method and linear regression as a new method to estimate solar radiation in Perlis, Nothern Malaysia", Solar Energy, Vol. 85, pp. 2871-2880, 2011.

[30] Owen, M. S., ASHRAE : Amercian Society of Heating, Refrigerating and Air-Coonditioning Engineers, Tullie Circle, N. E., Atlanta, GA 30329, 2009. 